\title{
A Framework of the Carbon-Neutral Auditing for Enterprises in China
}

\author{
Wei Zhang \\ Department of Accounting, Hunan University of Finance and Economics, Changsha, China. \\ Email: xxzhangwei@yahoo.com.cn
}

Received February $2^{\text {nd }}, 2013$; revised March 20 $0^{\text {th }}, 2013$; accepted April 20 2013

Copyright (c) 2013 Wei Zhang. This is an open access article distributed under the Creative Commons Attribution License, which permits unrestricted use, distribution, and reproduction in any medium, provided the original work is properly cited.

\begin{abstract}
This paper focuses on the framework of carbon-neutral auditing in China, and builds three modes to clarify the carbon neutral auditing in different circumstances which include individual enterprise, enterprises in a supply chain and enterprises in an eco-industry park meeting with the concept of circular economy. At the same time, it clarified the possible applications of carbon-neutral reports.
\end{abstract}

Keywords: Carbon Neutrality; Framework; Enterprises; Supply Chain; Circular Economy

\section{Introduction}

United Nations Framework Convention on Climate Change (UNFCCC) has aroused the global cooperation on the limitation of the emission of $\mathrm{CO}_{2}$ and other Greenhouse Gas (GHG) since 1992. Then, the Kyoto Protocol set the standards of $\mathrm{CO}_{2}$ emissions, built up three $\mathrm{CO}_{2}$ abasement cooperation mechanisms and allow exchanging carbon emissions credits under the restrictions, which provide the way for all kinds of enterprises to be carbon neutral. That is, for those enterprises, which can't be carbon neutral in the process of its own operation process, they can also be carbon neutral through buying carbon emissions credits to offset their overdose carbon emissions. China's first carbon neutral enterprise was born in August 5th, 2009. Tianping Aoto Insurance Company Ltd successfully bought 8026 Tons of carbon emission reduction credits provided by the Green Travel activities in Beijing in the duration of Olympic Games in 2008, by which it offset the whole carbon emissions produced in the process of operation from 2004 when it set up to the end of 2008 and became the first Chinese enterprise to be carbon neutral through buying carbon reduction credits voluntarily. Carbon-neutral through credits exchange among enterprises also realized in 2009 when Shanghai Jifeng Packaging \& Paper Industries Co., Ltd paid the price of 6266 Tons OF voluntary carbon Units (VCU) provided by Xiamen Heshi Environment Engineering Co., Ltd. As China's object is to decline the carbon emission per unit of gross domestic product (GDP) 40 percent to
45 percent by 2020 on the baseline of 2005, the decisionmaking level has paid great attention to this issue, and the newest decision of 18th Congress of the Communist Party of China emphasized on the practical issue of ecological construction and required which should be integrated into every aspects and the whole process of the construction of economy, politics, culture and society. Therefore, it's theoretically meaningful and practically useful to probe the framework of carbon neutral auditing of enterprises in China, which can be applied to monitor carbon reduction process and to make appraise of regional carbon reduction performance.

The following content of this paper includes four parts: Section 2 focuses on carbon-neutral auditing for independent enterprises. Section 3 discusses that of enterprises in a supply chain and Section 4 pays attention to enterprises in a recycling economy. Section 5 concludes the above discussion and gives some suggestions to the application of this framework under China's real environment.

\section{Possible Ways to Organize the Carbon-Neutral Auditing for Enterprises}

There are various enterprises in the markets. When we take a look at these enterprises from the perspective of carbon emissions, some of them can be neutral by taking carbon emissions reduction measures through improving and innovating technologies. They can reach carbon-neutral by themselves independently. Some of them may be carbon neutral through paying a price for buying units. 
Both of the two types of carbon neutrality happen on the level of individual enterprise. Carbon-neutral auditing work is not very complicated. As shown in Figure 1, this could be the level 1 of carbon-neutral auditing for enterprises. While there are also enterprises which can't be carbon neutral individually, they can if count carbon footprint by its supply chain. So the level 2 is for enterprises in a supply chain. The auditing objects turn to the supply chain; further, there are still enterprises can be carbon neutral if we take it in the recycling economy. Therefore, the level 3 concerns enterprises in a recycling economy.

\section{The Auditing Mode of Different Levels of Carbon-Neutral Auditing}

\subsection{Carbon-Neutral Auditing for Individual Enterprises}

To be individually carbon neutral means every enterprise should offset their carbon emissions, which should be the utmost object of every enterprise. As stated above, they either make some improvement on the facilities, technologies or buy carbon reduction units from other enterprises. So the auditing object is very clear, which is the individual enterprise. When auditing the carbon footprint, Life-Cycle Assessment is a general method adopted by Green House Gas Protocol, it consists of phases like: goal definition and scoping, emissions inventory analysis, impact assessment, and interpretation [1]. For individual enterprise, the focus of carbon foot-print audit is to define the scope of carbon emission. Practical method may be draw a flow chat of the whole business, based on which the carbon emission inventory can be finished. While enterprises seldom can be operated absolutely independent from others, carbon emissions are often shared by various enterprises such as transportation costs, logistics costs and etc. To assess the carbon footprint accurately, it's necessary to probe rational methods to allocate the shared carbon emissions. Allocation may be made according to the weight, the volume or the nature.

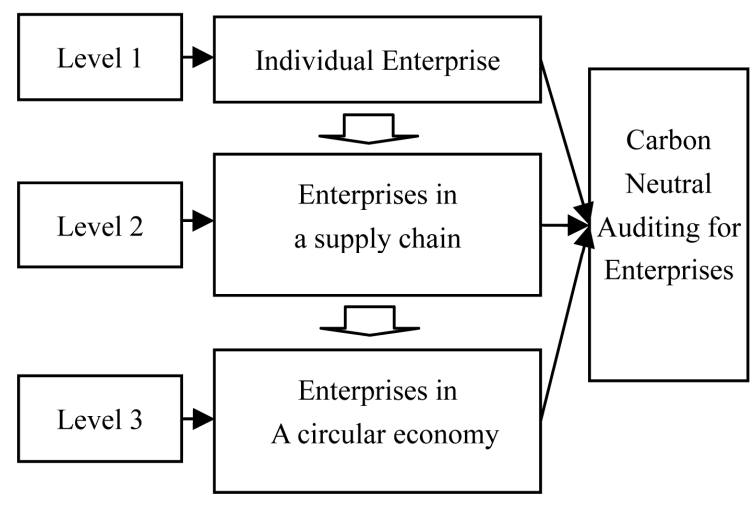

Figure 1. Levels of carbon neutral auditing.
While in this stage, when the carbon neutrality are not common for every enterprise, it's feasible that enterprises use the data they can get like the weight of goods, the mileage and kinds of transports to estimate the carbon emissions they should undertake. When more and more enterprises take part in carbon-neutral action, then allocation methods can be used for more accurate assessment. Except assessing the carbon footprint, to be carbon neutral, the carbon reduction be taken by the enterprises should also be appraised. When both the two sides of carbon neutrality are appraised, carbon-neutral auditing for individual enterprises can be carried out by internal audit as well as certified public account.

\subsection{Carbon-Neutral Auditing for Enterprises in a Supply Chain}

The carbon neutrality of enterprises in a supply chain takes the whole supply chain as the basis of carbon emissions assessment. As the supply chain includes all companies that take part in the process of supplying, production, allocation and sale before products reaching at customers, enterprises in a supply chain can be classified into upstream firms (supply activities), producers in the middle (production activities), transporters (storage and transportation activities) and downstream consumers (distribution activities) [2,3]. Though an enterprise may not be carbon neutral individually, the supply chain may be carbon neutral. For other enterprises, though they are carbon neutral, the supply chain may be not. Walmart estimates that over $90 \%$ of its emissions come from its supply chain rather than its own operations [4]. Under this circumstance, the most tackling problem lies in the collection of auditing evidence as it concerns not only single enterprises but a number of related enterprises. We introduce the carbon leader to solve this problem [5], which refers to firm that has the necessary means, motivation, and power to impose a footprint allocation rule on the whole supply chain by choice or otherwise. The internal auditor of carbon leader should take emissions of all firms in the supply chain into account. Take the manufactory industry for example, generally, the carbon leader is the core of the supply chain, so it's probable the producer to take this role in manufactory industry, as shown in Figure 2, it's in the middle of the supply chain and has more convenient connection with upstream as well as downstream firms. When the shared carbon footprint can be attributed to firms in the same supply chain in one way or another, then the carbon reduction should be made is clear for each firm. The carbon-neutral auditing carried out by outside auditors will certify carbon neutrality states according to these two sides, that is, carbon footprint produced and carbon reduction made by the supply chain. 


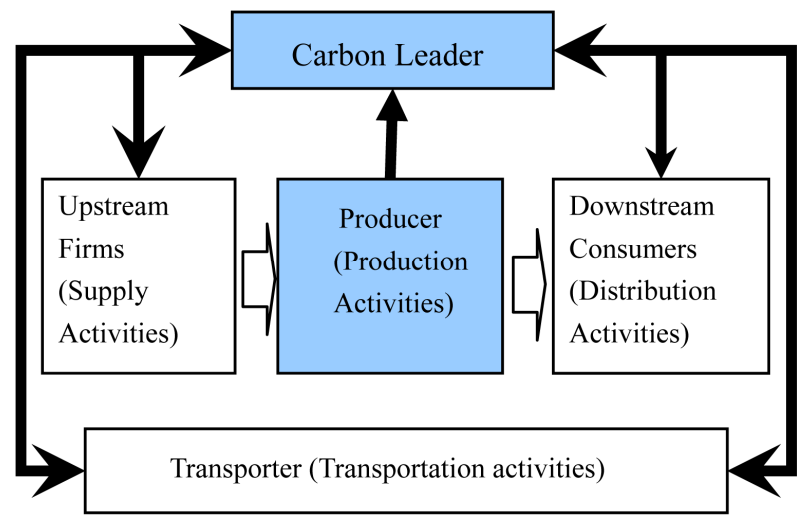

Figure 2. Carbon neutral audit for enterprises in a manufactory supply Chain.

\subsection{Carbon-Neutral Auditing for Enterprises in a Circular Economy}

The concept of circular economy was included in the scientific development since 2003 in China [6]. The Circular Economy Law was approved in 2008. Now, circular economy is implemented on various levels as cities, districts and the country as a whole, but the carbon-neutral auditing hasn't been started yet which would be an important means to supervise the effectiveness of circular economy. The 12th Five-Year Plan of the State Environmental Protection plans to build 50 eco-industrial parks on the basis of 65 approved eco-industrial parks. Eco-industrial parks aimed to realize low emissions of pollutants or zero emissions through reasonable organization of industry, building a circular utilization system of resources among enterprises, especially pay attention to the waste exchange, comprehensive utilization of resources. Carbon-neutral auditing of enterprises in an ecoindustrial park can also use the LCA method. Different from that of individual or supply chain enterprises, carbon-neutral auditing should emphasize more on the carbon reduction in the process of reduction, reuse, recycle. As the production process is the main source of pollutants for manufactory industry, so it may be the carbon leader which takes responsibility for internal carbonneutral auditing in the eco-industry park (as shown in Figure 3). The carbon leader of an eco-industry park takes charge on the collection of carbon emissions as well as carbon reductions from different enterprises, and makes cooperation with outside auditors to certify the carbon neutrality of the eco-industry park as a whole [7].

\section{The Carbon-Neutral Auditing Report and Its Possible Applications}

As mentioned above, there are three levels of carbonneutral of enterprises, accordingly, the carbon-neutral auditing reports are also of three levels respectively. Possible applications include making label in the related

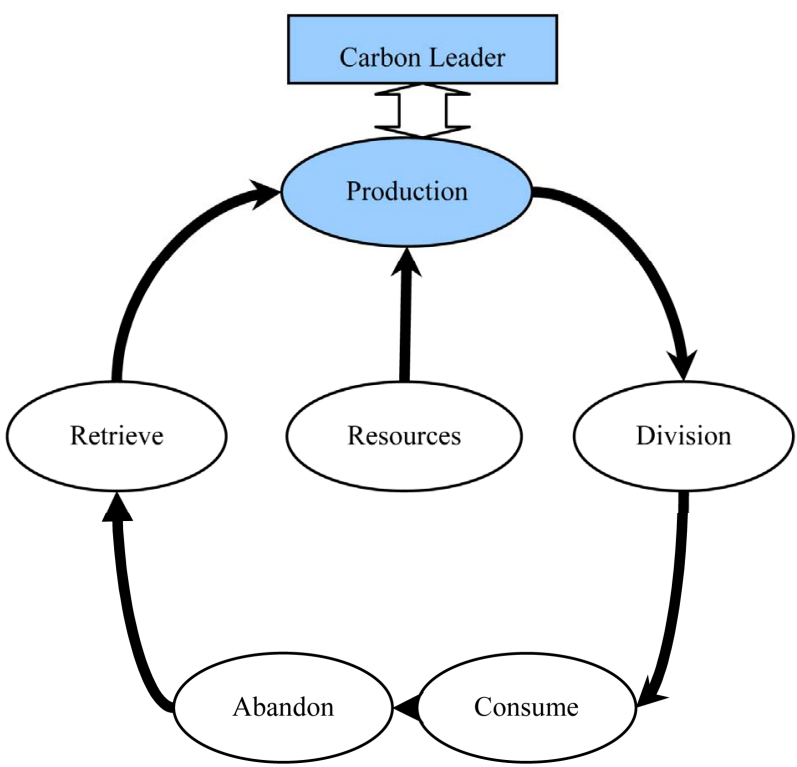

Figure 3. Carbon neutral audit for companies in an ecoindustry park.

products or services, meeting with the demand of keeping clear air from consumers. Recently, China's big fog has aroused wide concern about the carbon emissions from cars and factories, it's sure that some new carbon emission rules or laws will be formulated. There for, another important application of the carbon-neutral auditing report would be to meet with some mandatory requirements.

\section{Conclusion}

We focus on the framework of carbon-neutral auditing in China, and build three modes to clarify the carbon-neutral auditing in different circumstances, which include individual enterprise, enterprises in a supply chain and enterprises in an eco-industry park meeting with the concept of circular economy. The most important thing for auditing lies in the subject. The object should be determined and available. The auditing object not only concerns with whom to audit, but also what to audit. We introduced the "carbon leader" to take charge in the internal audit and the cooperation with outside audit and stated the differences of carbon-neutral auditing among three kinds of enterprises mentioned above and clarified the applications of carbon-neutral report.

\section{REFERENCES}

[1] WRI and WBCSD, "The Greenhouse Gas Protocol: A Corporate Accounting and Reporting Standard 2004," World Resources Institute and World Business Council for Sustainable Development.

http://www.ghgprotocol.org/files/gjgprotocolrevised. pdf

[2] S. Baiman, P. E. Fischer and M. V. Rajan, "Performance 
Measurement and Design in Supply Chains,” Management Science, Vol. 47, No. 1, 2001, pp. 173-188. doi:10.1287/mnsc.47.1.173.10673

[3] S. Benjaafar, Y. Li and M. Daskin, “Carbon Footprint and the Management of Supply Chains: Insights from Simple Models," Working Paper, University of Minnessota, Minneapolis, 2009.

[4] J. Birchall, "Walmart to Set Emissions Goals for Suppliers,” Financial Times, 25 February 2010, pp. 25-30.

[5] F. Caro, C. J. Corbett, T. Tan and R. Zuidwijk, “Carbon-
Optimal and Carbon-Neutral Supply Chains,” Electronic copy. http://ssrn.com/abstract=1947343

[6] J. N. Wang, "Circular Economy Is a Strategy Choice for Environmental Protection in 21st Century," Research of Environmental Sciences, Vol. 15, No. 3, 2002, pp. 34-37.

[7] X. M. Liu, Z. H. Li, F. C. Fan and X. L. Wang, "Comprehensive Evaluation of Agro-Recycling Economy of City Field in Hebei Province Based on the Osculation Value Method," Chinese Agriculture Science Bulletin, Vol. 28, No. 11, 2012, pp. 145-149. 